\title{
Cancer Risks from Germline P53 Mutations
}

\author{
Thierry Frebourg* and Stephen H. Friend * * \\ *Division of Molecular Genetics, Massachusetts General Hospital Cancer Center, MGH East, Charlestown, Massachusetts 02129; \\ and ${ }^{\ddagger}$ Department of Pediatrics, Division of Hematology-Oncology, The Children's Hospital, \\ Dana-Farber Institute, Harvard Medical School, Boston, Massachusetts 02114
}

\section{Introduction}

The malignant transformation of a cell is a complex process resulting from several molecular events. The considerable development of molecular biology during the last decade has allowed a recognition that these events fall into two distinct categories: the activation of protooncogenes and the inactivation of tumor suppressor genes. Whereas research was initially focused on oncogenes, tumor suppressor genes have quickly become one of the most active fields in cancer research. Tumor suppressor genes are genes whose inactivation is required for the malignant transformation of a cell. The involvement of such genes in cancer was initially suggested by in vitro fusion experiments between normal and malignant cells (1). In most cases, such fusions result in hybrid cells which are, in contrast to the parental malignant cell, not tumorigenic in nude mice. Furthermore, these hybrids can become tumorigenic during their propagation in vitro, and this evolution is associated with the loss of chromosomes deriving from the normal parental cell. These observations suggested that genes deriving from the normal parental cell were able to control the expression of the malignant phenotype.

Another indication that tumor suppressor genes were involved in the development of human cancers was the observation of specific deletions in human tumors. Analysis of tumor and constitutional DNA from the same individual with polymorphic probes usually reveals a loss of heterozygosity at specific loci in the tumor (2). This observation indicated that the loss of specific genes was required for the development of human cancers. Other clues about tumor suppressor genes came from epidemiologic studies. To explain the epidemiology of retinoblastoma which can be sporadic or familial, Alfred Knudson postulated the "two hit" hypothesis (3). According to this model, retinoblastoma results from two successive events which are the inactivation of both copies of a gene, the $R B$ gene. In familial forms of retinoblastoma, one allele of the $R B$ gene is inactivated in the germline and a second event occurring at the somatic level will inactivate the other allele. In sporadic cases, two somatic events are required to inactivate the $R B$ gene. Genetic and molecular studies have now demonstrated the validity of this model.

Address reprint requests to Dr. Thierry Frebourg, Division of Molecular Genetics, Massachusetts General Hospital Cancer Center, Building 149, 13th Street, Charlestown, MA 02129.

Received for publication 3 June 1992.

J. Clin. Invest.

(C) The American Society for Clinical Investigation, Inc. $0021-9738 / 92 / 11 / 1637 / 05 \quad \$ 2.00$

Volume 90, November 1992, 1637-1641
The observation that mutations of tumor suppressor genes can occur not only at the somatic level but also in the germline has important clinical implications. Detection of germline mutations in tumor suppressor genes should allow the identification of subjects at high risk to develop cancer. During the last two years, many studies have been focused on the germline mutations of the p53 tumor suppressor gene. This review will present data that show that individuals with germline p53 mutations have a high risk of developing a wide spectrum of malignancies.

\section{The p53 tumor suppressor gene}

The p53 gene encodes a nuclear phosphoprotein which was originally described in 1979 as a protein able to form an oligomeric complex with the SV40 large T antigen in SV40 transformed cells (4). The high levels of p53 observed in transformed cells and the ability of the p53 gene to cooperate with the ras genes in rat embryo fibroblasts transformation assays initially indicated that the p53 gene was an oncogene. 10 years later, it was demonstrated that only the mutant forms of p53 had transforming properties (4). Furthermore, two lines of data have shown that the wild-type form of the p53 gene can be considered as a tumor suppressor gene: (a) Somatic alterations of the p53 gene have been reported in a spectrum of human cancers, suggesting that this event is required for the malignant transformation of many human cells (4-6). Mutation of the p53 tumor suppressor gene is currently the most frequently detected genetic alteration in human cancers. These changes are mostly missense mutations. The human p53 gene is located on chromosome $17 p$ (region 17p13), contains 11 exons (the first exon does not encode protein sequences), and the p53 protein is composed of 393 amino acids. $98 \%$ of the 280-base substitution mutations reported so far in malignant tumors are clustered between exons 5 and 8 and are localized in four evolutionarily conserved domains of p53: domain II (codons 117 to 142), domain III (codons 171 to 181 ), domain IV (codons 234 to 258 ) and domain V (codons 270 to 286) (4-6). (b) The expression of wild-type p53 is able to suppress the transformation of cells by others oncogenes $(7,8)$, to inhibit the growth of malignant cells in vitro (9-15) and to suppress the tumorigenic phenotype of transformed cells (16). Many studies have suggested that the ability of the wild-type protein to block the growth of malignant cells in vitro results from a specific effect of $p 53$ on the $G 1$ phase of the cell cycle $(4,12,17)$.

Analysis of the $17 \mathrm{p}$ chromosome with polymorphic probes in human cancers containing p53 mutations has revealed that the wild-type allele is quite often lost during tumor development (4). This result indicates that in most tumors, both p53 alleles are inactivated, one through a point mutation, the other through a deletion. This suggests that most mutations at the 
p53 locus are recessive and that p53 inactivation can be explained by the "two hits" model proposed by Knudson for the $R B$ gene (3). Nevertheless, the ability of some mutant p53 proteins, observed in human tumors, to transform primary rodent cells in cooperation with the ras genes suggests that mutant p53 can inactivate the endogenous wild-type protein (4). The proposed mechanism for this dominant effect of the mutant protein involves the formation of oligomers between the wild-type and the mutant proteins $(4,16)$. The mutant p53 proteins are also able to form complexes with the constitutively expressed member of the heat shock proteins family, the hsc70 protein $(18,19)$. Therefore, these interactions would trap and inactivate the wild-type p53 protein. This would explain the transdominant negative effect of some mutations.

The molecular mechanisms by which the p53 gene is able to act as a tumor suppressor gene remain unclear. Fusion experiments with the DNA binding domain of the yeast protein GAL-4 have suggested that p53 could be a transcriptional activator $(20,21)$. The $\mathrm{p} 53$ protein could therefore control the cell cycle by activating the genes that suppress cell proliferation. Nevertheless, the observation that some p53 mutants retained the transcriptional activity in these experiments was initially confusing. Results obtained in Bert Vogelstein's laboratory confirm that p53 has transcriptional activity. Wild-type p53 has been shown to bind specifically in vitro to DNA sequences containing the TGCCT motif (22). Precise mapping of the binding sequences has revealed a consensus binding site consisting of two copies of the 10-bp motif 5'-PuPuPuC(A/T)(T/ A) GPyPyPy-3' separated by 0-13 bp (23). Biological significance of this binding has recently been demonstrated by cloning the motif upstream of a weak promoter controlling the expression of the CAT (chloramphenicol acetyl-transferase) gene. Cotransfection experiments of this CAT construct with a p53 expression vector have shown that p53 was able to transactivate the recombinant promoter. In contrast to the wild-type protein, none of the mutants tested so far have been found to have a transcriptional activity (24).

The second speculated role of p53 is the control of DNA replication. This biological activity was suggested by works on the replication of the SV40 virus. The wild-type form of p53 is able to inhibit the binding of SV40 large T to the cellular $\alpha$ polymerase which is required for SV40 DNA replication (4). The wild type protein is also able to inhibit the helicase activity of $T$ antigen which facilitates DNA replication (4). It has been speculated that SV40 T antigen had a cellular homogue which is involved in the control of DNA replication. Therefore, p53 would bind this cellular homologue and would inhibit DNA replication.

\section{Identification of germline p53 mutations}

Germline $p 53$ mutations in the Li-Fraumeni syndrome. Germline p53 mutations were initially reported in patients with the rare Li-Fraumeni syndrome (LFS), a family cancer syndrome in which affected relatives develop a diverse set of malignancies including breast carcinomas, sarcomas, and brain tumors ( 25 , 26). The transmission of the LFS is autosomal dominant and the clinical definition requires: $(a)$ an individual (the proband) with a sarcoma diagnosed before age $45 ;(b)$ a first degree relative with cancer before age 45; and (c) another first or second

1. Abbreviation used in this paper: LFS, Li-Fraumeni syndrome. degree relative with either a sarcoma diagnosed at any age or any cancer diagnosed under age $45(25)$. The relative risk of cancer in LFS during childhood has been estimated to 20 (26). Several problems hindered the cloning of the LFS gene using linkage analysis: $(a)$ few individuals are readily available for study because the disorder is very rare and the lethality of the tumors is significant; $(b)$ the clinical diagnosis is sometimes difficult because of the lack of an unambiguous definition of the syndrome; $(c)$ there are no associated specific chromosomal alterations that might identify a marker site. One reasonable candidate gene for the LFS was the p53 gene because somatic mutations of the p53 gene had been reported in most of the tumors observed in the LFS. Furthermore, transgenic mice that overexpressed mutant p53 developed a wide spectrum of tumors, many of which are component tumors of the LFS in human (27). Initial study of the p53 gene in fibroblasts and lymphocytes of five families with LFS, using the polymerase chain reaction and nucleic acid sequencing, identified germline p53 mutations in the five families (28). These mutations were missense mutations in a highly conserved region of the protein. Analysis of one LFS family, using a highly polymorphic DNA sequence on chromosome $17 \mathrm{p}$, confirmed the consegregation of the p53 allele with the LFS (28). Furthermore, the tumors that were tested had lost the remaining wild-type p53 allele (28). This work suggested that germline p53 mutations might provide one explanation for the LFS. Germline p53 mutations in LFS have also been documented by other investigators (2931 ). Importantly, there are also other LFS families in which it has not been possible to detect any germline p53 mutations (31, Friend, S. H., and N. Barbier, unpublished results). These negative results must be analyzed with caution. Before concluding that germline p53 mutations are not present in families with LFS, the sequencing of the entire p53 coding region is required. The possibility that germline p53 mutations are not the only molecular basis of the LFS must be also considered. For example, genetic alterations affecting proteins in the p53 signaling pathway could produce phenotypes identical to the LFS (31a-c).

Germline p53 mutations outside the Li-Fraumeni syndrome. Since the original report of germline p53 mutations in LFS, many investigators have looked for germline p53 mutations in patients with cancers which are component tumors of the LFS. One striking feature of the affected members in families with LFS is the high frequency at which they develop second malignancies. Almost $50 \%$ of the affected members develop more than one malignant neoplasm. This observation led our group to analyze children and young adults with second malignant neoplasms, who did not have any history consistent with LFS. This study revealed that four of the 59 patients with second malignant neoplasms had germline p53 mutations (32). Germline p53 mutations also have been found in patients with sarcomas $(33,34)$, in a patient with a brain tumor (35), and in patients with familial breast cancer $(36,37)$. The frequency of germline p53 mutations in women with breast cancer appears to be $<1 \%(36,37)$.

These reports indicate that germline p53 mutations are found outside LFS. Two important observations can be made from these studies. First, germline p53 mutations have been observed mostly in patients with an unusual history of cancers, i.e., multiple malignancies, or a family history of cancers. For example, in the study on sarcomas by Toguchida et al. (33), 
the frequency of germline p53 mutations in randomly chosen sarcoma patients was very low (2:181) and both positive patients had a remarkable family history of cancers. In the same report, the frequency of germline p53 mutations was extremely high in patients who were selected for the study because they had either multiple primary cancers or an unusual family of cancers (6:15). The germline p53 mutation reported by Metzger et al. in a case of an intracranial ependydoma (34) was observed in a patient with a strong family of cancer. The three patients with breast cancer (3:363) who had a germline p53 mutation had also a family history of cancers $(36,37)$. The other important observation regarding germline p53 mutations is that, in most of the cases, these mutations have been shown to be inherited. Only 2 of 18 germline p 53 mutations have been shown so far to be de novo (Table I). These observations suggest that de novo germline p53 mutations are rare in contrast to germline $R B$ mutations that occur de novo in 85 percent of retinoblastomas. Germline p53 mutations are therefore probably most often inherited.

Distribution and nature of germline p53 mutations. Initial studies on germline p53 mutations in LFS have suggested that the distribution of germline mutations in contrast to that of somatic mutations could be restricted. The first described germline mutations were found in exon 7 of the p53 gene in the conserved region IV $(28,29)$. It was therefore speculated that only certain mutations might be tolerated in the germline (28). Analysis of germline mutations in LFS patients and in others patients clearly indicate that germline mutations are widely distributed among the $\mathrm{p} 53$ gene between amino acid residues 72 and 325 (Table I).

Germline mutations reported so far are mostly missense mutations ( Table I) but the study by Toguchida et al. indicates that nonsense and frameshift mutations of the p53 gene can also be found in the germline (33). Most of the missense mutations are within conserved domains of the protein (Table I). The only missense mutation which is located outside of a conserved domain is in codon $\mathbf{3 2 5}$ which is conserved in monkey, mouse, and rat (32).

\section{Involvement of germline p53 mutations in cancer development}

The involvement of a germline p53 mutation in the development of cancer can theoretically be demonstrated by genetic analysis. Nevertheless, genetic analysis is of limited use for germline p53 mutations for the following reasons: $(a)$ genetic analysis can be performed only if the patients have a strong familial history of cancers and germline mutations have been reported in patients with a limited number of affected relatives; (b) in kindreds with a high incidence of cancers, like in the LFS families, genetic analysis is often limited by the few number of available samples since the lethality is usually very high; $(c)$ the development of a cancer in a patient who does not carry the germline p53 mutation observed in the proband can correspond to a sporadic case of cancer; $(d)$ tumors will not necessary develop in all patients with a germline p53 mutations at the time of genetic analysis since the age of onset is variable. For these reasons, the coinheritance of a mutant p53 allele with cancer has been clearly demonstrated in only one extented family with $\mathrm{Li}$-Fraumeni syndrome (30).

When genetic analysis is not possible, it is necessary to demonstrate that these mutations have inactivated the tumor suppressor function of the p53 protein. Most of the germline p53 mutations described so far are missense mutations (Table I) and it is not obvious that all of these missense mutations have disrupted $\mathrm{p} 53$ function. These missense mutations could have a biological significance but also could instead represent previ-

Table I. Germline Mutations of the p53 Gene

\begin{tabular}{|c|c|c|c|c|}
\hline Codon & $\begin{array}{l}\text { Nucleotide } \\
\text { change }\end{array}$ & $\begin{array}{l}\text { Amino-acid } \\
\text { change }\end{array}$ & $\begin{array}{l}\text { Observed } \\
\text { in }\end{array}$ & Reference \\
\hline $71-72$ & 1-bp insertion & Frame-shift & OS & (33) \\
\hline 120 & AAG $\rightarrow$ TAG & Lys $\rightarrow$ Stop & MPC & (33) \\
\hline 133 & ATG $\rightarrow$ ACG & Met $\rightarrow \mathrm{Thr}$ & LFS* & (30) \\
\hline $151-152$ & 1-bp insertion & Frame-shift & LFS* & (33) \\
\hline \multirow[t]{2}{*}{181} & $\mathrm{CGC} \rightarrow \mathrm{TGC}$ & Arg $\rightarrow$ Cys & $\mathbf{B C}^{*}$ & $(36)$ \\
\hline & CAC & His & $\mathrm{BC}^{*}$ & $(37,38)$ \\
\hline $209-210$ & 2-bp deletion & Frame-shift & MFH & (33) \\
\hline 241 & $\mathrm{TCC} \rightarrow \mathrm{TTC}$ & Ser $\rightarrow$ Phe & $\mathrm{MPC}^{\ddagger}$ & (33) \\
\hline 242 & $\mathrm{TGC} \rightarrow \mathrm{TAC}$ & Cys $\rightarrow$ Tyr & BT & (35) \\
\hline \multirow[t]{3}{*}{245} & GGC $\rightarrow$ TGC & Gly $\rightarrow$ Cys & LFS* & (28) \\
\hline & GAC & Asp & LFS $^{*}$ & (29) \\
\hline & AGC & Ser & $\mathrm{OS}^{*}, \mathrm{BC} *$ & $(33,37)$ \\
\hline \multirow[t]{2}{*}{248} & $\mathrm{CGG} \rightarrow \mathrm{TGG}$ & Arg $\rightarrow$ Trp & LFS $^{*}, \mathrm{SMN}^{*}$ & $(28,31,32)$ \\
\hline & CAG & Gln & LFS $^{*}$, MPC $^{\ddagger}$ & $(31,33)$ \\
\hline 258 & GAA $\rightarrow$ AAA & Glu $\rightarrow$ Lys & LFS* & (28) \\
\hline 273 & $\mathrm{CGT} \rightarrow \mathrm{CAT}$ & $\mathrm{Arg} \rightarrow \mathrm{His}$ & SMN & (32) \\
\hline 282 & $\mathrm{CGG} \rightarrow \mathrm{TGG}$ & Arg $\rightarrow$ Trp & $\mathrm{SMN}^{*}, \mathrm{OS}^{*}, \mathrm{MOS}$ & $(32,33,34)$ \\
\hline 325 & GGA $\rightarrow$ GTA & Gly $\rightarrow$ Val & $\mathrm{SMN}^{*}$ & (32) \\
\hline
\end{tabular}

\footnotetext{
*Inherited mutation; ${ }^{\ddagger}$ new germline mutation. OS, Osteosarcoma; MPC, multiple primary cancers; BC, breast cancer; MFH, malignant fibrous histiocytoma; BT, brain tumor; SMN, second malignant neoplasms; MOS, multifocal osteogenic sarcoma.
} 
ously undetected rare polymorphisms. Therefore, we have undertaken a systematic analysis of the biological properties of germline p53 mutants to determine if the corresponding mutations have inactivated the p53 gene and thereby provide an increased risk for cancer. Constructs expressing germline mutant proteins observed in patients with different clinical presentations ( Li-Fraumeni syndrome, second malignancies, familial breast carcinoma) were stably transfected into the Saos-2 osteosarcoma cell line in which the endogenous p53 gene is completely inactivated (38). The expression of transfected wildtype $\mathrm{p} 53$ blocks the progression of the cell cycle before $S$ phase, and that expression of the wild-type protein is not tolerated in stably transfected Saos-2 cells (12). Transfection of the plasmids expressing the germline mutants (except one mutant at codon 181) resulted in approximately eightfold more stable colonies than when the plasmid expressing wild-type p53 was transfected (38). Analysis of p53 expression in stable transfectants revealed that, most of the colonies derived from the transfections with the plasmids encoding the germline mutants expressed high levels of $\mathrm{p} 53$ protein. These results demonstrated that these germline mutant proteins were unable to inhibit the growth of malignant cells. In contrast, none of the colonies derived from the transfection with the plasmid expressing the mutant protein at codon 181 or the wild-type protein, were found to express p53. This result indicates that the expression of the mutant protein at codon 181, like the expression of the wild-type p53, was incompatible with the growth of malignant cells in vitro (38).

We then determined whether germline p53 mutants shared certain unique structural properties (38). Many inactivating mutations, which have been detected in sporadic tumors, have been shown to produce structural modifications of p53: (a) most of the mutant proteins are recognized by the antibody PAb240 which is specific for a mutant conformation (39); (b) frequently, the mutant proteins complex with hsc70 (18); and (c) all the mutations observed in sporadic tumors and analyzed so far have been shown to disrupt the binding of p53 to SV40 large $T$ antigen (4). This study revealed that the structural properties of the germline p53 mutants show a high degree of heterogeneity. However, with the exception of the mutant at codon 181 , none of the germline mutants retained all the structural features of the wild-type protein (38).

Therefore, the functional and structural studies of the germline mutants revealed one germline mutant (at codon 181 ) to be identical to the wild-type p53 in our assays. We speculated that this germline mutation was not associated with an increased risk for cancer. To test this hypothesis, we performed genetic analysis on the family with this germline p53 mutation (38). This mutation had been detected in a patient with a familial breast cancer (37). Genetic analysis provided two pieces of data suggesting that the codon 181 mutation was not associated with the development of cancer in all members of this family. The mutation was not present in the germline of a family member who developed two cancers. More importantly, the codon 181 mutant was somatically lost during the development of a cancer in another relative (38). These results indicate that germline mutations which change the amino-acid sequence in the conserved domains of p53 will not always be associated with an increased risk for early cancer. Therefore, before associating a germline p53 mutation with the development of cancer, it is prudent to consider its functional significance.
The involvement of germline p53 inactivating mutations in the development of cancers was recently investigated in vivo using mice deficient for p53. A null mutation was introduced into the p53 gene by homozygous recombination in murine embryonic stem cells (40). Mice homozygous for the null allele were developmentally normal but most of them (74\%) developed neoplasms by six months of age (40). These results confirm that germline inactivation of the $\mathrm{p} 53$ gene predisposes to cancer.

\section{Conclusion}

Analytical studies performed during the two last years have identified germline p53 mutations in patients with cancer. Genetic and biological studies have emphasized the involvement of these germline mutations in cancer development. In contrast to germline mutations observed in other tumor suppressor genes like the $R B$ or the $W T 1$ gene, germline p53 mutations appear to predispose to the development of malignant tumors in many tissues: breast carcinomas, soft tissue sarcomas, osteosarcomas, brain tumors, and leukemias.

Detection of a germline p53 mutation in one patient represents at present time an intensive work of molecular biology. The classical approach requires five successive steps: PCR amplification, cloning of the PCR amplified fragment into a plasmid sequencing vector, transformation of bacteria with the recombinant plasmid, DNA minipreparations and sequence of several clones to ensure the detection of both the wild-type and mutant p53 alleles (28). The entire coding region of p53 must be sequenced since germline p53 mutations are widely distributed along the gene. Alternate strategies have been developed to decrease the effort required to screen large numbers of samples. Direct sequencing $(29,30,33,34)$ and methodologies based on the modification of the DNA conformation, like single strand conformation polymorphism $(33,34)$, denaturing gradient gel electrophoresis (35), or constant denaturant gel electrophoresis $(32,37)$, have been successfully used for the detection of germline p53 mutations.

The identification of a germline p53 mutation in a patient must be followed by genetic or molecular studies before concluding that a given germline mutation provides a high risk for cancer. Biological studies of germline p53 mutations (38) have indicated that rare polymorphisms, variants without phenotypical expression, will be identified in p 53 as have been found in other genes such as the $\beta$-globine gene. An important question to address in the future will be to determine if all the significant germline p53 mutations provide the same risk for cancer development. A recent study has shown that both p53 alleles are constitutionally expressed in normal cells derived from LFS patients (41). It has been speculated that some p53 mutations could be dominant over the wild-type protein. This transdominant negative effect would result in a complete inactivation of $\mathrm{p} 53$ function in a patient with a germline p53 mutation. One can speculate that germline p53 mutants with a transdominant effect might be associated with a poor prognosis. Therefore, it might be important to determine which protein, the mutant or the wild-type, is dominant over the other.

The demonstration of the involvement of a specific germline p53 mutation in cancer development requires an intensive analysis. For this reason, at the present time, generalized screening of patients is not indicated. This screening should probably be restricted to specific groups in which germline mutations have been found at a high frequency: individuals with a 
strong family cancer history and patients with multiple primary cancers. Identification of germline p53 mutations in these groups should allow the detection of individuals and families at high risk to develop cancers.

The most important question in the next years will be to determine the care of presymptomatic mutation carriers. Vital ethical and medical issues regarding this type of predictive screening have already begun to be addressed (42).

\section{References}

1. Harris, H., O. J. Miller, G. Klein, P. Worst, and T. Tachibana. 1969. Suppression of malignancy by cell fusion. Nature (Lond.). 223:363-357.

2. Weinberg, R. A. 1991. Tumor suppressor genes. Science (Wash. DC). 254:1138-1146.

3. Knudson, A. G., Jr. 1971. Mutation and cancer. Statistical analysis of retinoblastoma. Proc. Natl. Acad. Sci. USA. 68:820-823.

4. Levine, A. J., J. Momand, and C. A. Finlay. 1991. The p53 tumour suppressor gene. Nature (Lond.). 351:453-456.

5. Hollstein, M., D. Sidransky, B. Vogelstein, and C. C. Harris. 1991. p53 mutations in human cancers. Science (Wash. DC). 253:49-53.

6. Caron de Fromentel, C., and T. Soussi. 1992. The p53 tumor suppressor gene: a model for investigating human mutagenesis. Genes, Chrom. Cancer. 4:115.

7. Finlay, C. A., P. W. Hinds, and A. J. Levine. 1989. The p53 proto-oncogene can act as a suppressor of transformation. Cell. 57:1083-1089.

8. Eliyahu, D., D. Michalovitz, S. Eliyahu, O. Pinhasi-Kimhi, and M. Oren. 1989. Wild-type p53 can inhibit oncogene mediated focus transformation. Proc. Natl. Acad. Sci. USA. 86:8763-8767.

9. Baker, S. J., S. Markowitz, E. R. Fearon, J. K. V. Wilson, and B. Vogelstein. 1990. Suppression of human colorectal carcinoma cell growth by wild-type p53. Science (Wash. DC). 249:912-915.

10. Mercer, W. E., M. Amin, G. J. Sauve, E. Appella, S. J. Ullrich, and J. W. Romano. 1990. Wild type human p53 is antiproliferative in SV40-transformed hamster cells. Oncogene. 5:973-980.

11. Mercer, W. E., M. T. Shields, M. Amin, G. J. Sauve, E. Appella, J. W. Romano, and S. J. Ullrich. 1990 . Negative growth regulation in a glioblastoma tumor cell line that constitutionally expresses human wild-type p53. Proc. Natl. Acad. Sci. USA. 87:6166-6170.

12. Diller, L., J. Kassel, C. E. Nelson, M. A. Gryka, G. Litwak, M. Gebhardt B. Bressac, M. Ozturk, S. J. Baker, B. Vogelstein, and S. H. Friend. 1990. p5 functions as a cell cycle control protein in osteosarcomas. Mol. Cell. Biol. 10:5772-5781.

13. Johnson, P., D. Gray, M. Mowat, and S. Benchimol. 1991. Expression of wild-type p53 is not compatible with continued growth of p53-negative tumor cells. Mol. Cell. Biol. 11:1-11.

14. Casey, G., M. Lo-Hsueh, M. E. Lopez, B. Vogelstein, and E. J. Stanbridge. 1991. Growth suppression of human breast cancer cells by the introduction of a wild-type p53 gene. Oncogene. 6:1791-1797.

15. Isaacs, W. B., B. S. Carter, and C. M. Ewing. 1991. Wild type p53 suppresses growth of prostate cancer cells containing mutant p53 alleles. Cancer Res. $51: 4716-4720$.

16. Chen, P. L., Y. Chen, R. Bookstein, and W. H. Lee. 1990. Genetic mechanisms of tumor suppression by the human p53 gene. Science (Wash. DC). 250:1576-1580.

17. Martinez, J., I. Georgoff, J. Martinez, and A. J. Levine. 1991. Cellular localization and cell cycle regulation by a temperature-sensitive p53 protein. Genes \& Dev. 5:151-159.

18. Finlay, C. A., P. W. Hinds, T. H. Tan, D. Elihayu, M. Oren, and A. J. Levine. 1988. Activating mutations for transformation by p53 produce a gene product that forms a hsc70-p53 complex with an altered half-life. Mol. Cell. Biol. 8:531-539.

19. Hinds, P. W., C. A. Finlay, R. S. Quartin, S. J. Baker, E. R. Fearon, B. Vogelstein, and A. J. Levine. 1990. Mutant p53 DNA clones from human colon carcinomas cooperate with ras in transforming primary rat cells: a comparison of the "hot spot" mutant phenotypes. Cell Growth \& Diff. 1:571-580.

20. Fields, S., and S. K. Jang. 1990. Presence of a potent transcription activating sequence in the p53 protein. Science (Wash. DC). 249:1046-1049.

21. Raycroft, L., H. Wu, and G. Lozano. 1990. Transcriptional activation by wild-type but not transforming mutants of the p53 anti-oncogene. Science (Wash. DC). 249:1049-1051.

22. Kern, S. E., K. W. Kinzler, A. Bruskin, D. Jarosz, P. Friedman, C. Prives, and B. Vogelstein. 1991. Identification of p53 as a sequence-specific DNA-binding protein. Science (Wash. DC). 252:1708-1711.

23. El-Deiry, W. S., S. E. Kern, J. A. Pietenpol, K. W. Kinzler, and B. Vogel- stein. 1992. Definition of a consensus binding site for p53. Nature Genetics. 1:45-49.

24. Kern, S. E., J. A. Pientenpol, S. Thiagalingam, A. Seymour, K. W. Kinzler, and B. Vogelstein. 1992. Oncogenic forms of p53 inhibit p53-regulated gene expression. Science (Wash. DC). 256:827-830.

25. Li, F. P., J. F. Fraumeni, Jr., J. J. Mulvihill, W. A. Blattner, M. G. Dreyfus, M. A. Tucker, and R. W. Miller. 1988. A cancer family syndrome in twenty four kindreds. Cancer Res. 48:5358-5362.

26. Garber, J. E., A. M. Goldstein, A. F. Kantor, M. G. Dreyfus, J. F. Fraumeni, and F. P. Li. 1991. Follow-up study of twenty-four families with Li-Fraumeni syndrome. Cancer Res. 51:6094-6097.

27. Lavigueur, A., V. Maltby, D. Mock, J. Rossant, T. Pawson, and A. Berstein. 1989. High incidence of lung, bone, and lymphoid tumors in transgenic mice overexpressing alleles of p53 oncogene. Mol. Cell. Biol. 9:3982-3991.

28. Malkin, D., F. P. Li, L. C. Strong, J. F. Fraumeni, C. E. Nelson, D. H. Kim, J. Kassel, M. A. Gryka, F. Z. Bischoff, M. A. Tainsky, and S. H. Friend. 1990. Germline p53 mutations in a familial syndrome of breast cancer sarcomas and other neoplasms. Science (Wash. DC). 250:1233-1238.

29. Srivastava, S., Z. Zou, K. Pirollo, W. Blattner, and E. H. Chang. 1990 Germline transmission of a mutated p53 gene in a cancer-prone family with Li-Fraumeni syndrome. Nature (Lond.). 348:747-749.

30. Law, J. C., L. C. Strong, A. Chidambaram, and R. E. Ferrell. 1991. A germ line mutation in exon 5 of the p53 gene in an extended cancer family. Cancer Res. 51:6385-6387.

31. Santibanez-Koref, M. F., J. M. Birch, A. L. Hartley, P. H. Morris Jones, A. W. Craft, T. Eden, D. Crowther, A. M. Kelsey, and M. Harris. 1991. p53 germline mutations in Li-Fraumeni syndrome. Lancet. 338:1490-1491.

3la.Moman J., G. P. Zambetti, D. C. Olson, D. George, and A. J. Levine. 1992. The $m d m-2$ oncogene product forms a complex with the p53 protein and inhibits p53-mediated transactivation. Cell. 69:1237-1245.

31b.Oliner, J. D., K. W. Kinzler, P. S. Meltzer, D. L. Georges, and B. Vogelstein. 1992. Amplification of a gene encoding a p53-associated protein in human sarcomas. Nature (Lond.). 358:80-83.

31 c.Barnes, D. M., A. M. Hanby, C. E. Gillett, S. Mohammed, S. Hodgson, L. G. Bobrow, I. M. Leigh, T. Purkis, C. Macgeoch, N. K. Spurr, et al. 1992. Abnormal expression of wild type p53 protein in normal cells of a cancer family patient. Lancet, 340:259-263.

32. Malkin, D., K. W. Jolly, N. Barbier, A. T. Look, S. H. Friend, M. C. Gebhardt, T. I. Andersen, A. L. Børresen, F. P. Li, J. Garber, M. L. Greenberg, and L. C. Strong. 1992. Germline mutations of the p53 tumor-suppressor gene in children and young adults with second malignant neoplasms. $N$. Engl. J. Med. 326:1309-1315.

33. Toguchida, J., T. Yamaguchi, S. H. Dayton, R. L. Beauchamp, G. E. Herrera, K. Ishizaki, T. Yamamuro, P. A. Meyers, J. B. Little, M. S. Sasaki, et al. 1992. Prevalence and spectrum of germline mutations of the p53 gene among patients with sarcomas. N. Engl. J. Med. 326:1301-1308.

34. Iavarone, A., K. K. Matthay, T. M. Steinkirchner, and M. A. Israel. 1992. Germ-line and somatic p53 gene mutations in multifocal osteogenic sarcoma. Proc. Natl. Acad. Sci. USA. 89:4207-4209.

35. Metzger, A. K., V. C. Sheffield, G. Duyk, L. Daneshvar, M. S. B. Edwards, and P. H. Cogen. 1991. Germ-line mutation in the p53 gene in a patient with an intracranial ependymoma. Proc. Natl. Acad. Sci. USA. 88:7825-7829.

36. Sidransky, D., T. Tokino, K. Helzlsouer, B. Zehnbauer, G. Raush, B. Shelton, L. Prestigiacomo, B. Vogelstein, and N. Davidson. 1992. Inherited p53 gene mutations in breast cancer. Cancer Res. 52:2984-2986.

37. Børresen, A. L., T. I. Andersen, J. Garber, N. Barbier, S. Thorlacius, J. Eyf jord, L. Ottestad, B. S. Sorensen, M. Pharm, E. Hovig, and S. H. Friend. 1992 Screening for germ-line TP53 mutations in breast cancer patient. Cancer Res. 52:3234-3236.

38. Frebourg, T., J. Kassel, K. T. Lam, M. A. Gryka, N. Barbier, T. I. Andersen, A. L. Børresen, and S. H. Friend. 1992. Germline mutations of the p53 tumor suppressor gene in patients with high risk for cancer inactivate the p53 protein. Proc. Natl. Acad. Sci. USA. 89:6413-6417.

39. Gannon, J. V., R. Greaves, R. Iggo, and D. P. Lane. 1990. Activating mutations in $\mathbf{5} 53$ produce a common conformational effect. A monoclonal antibody specific for the mutant form. EMBO (Eur. Mol. Biol. Organ.) J. 5:15951602.

40. Donehower, L. A., M. Harvey, B. L. Slagle, M. J. McArthur, C. A. Montgomery, Jr., J. S. Butel, and A. Bradley A. 1992. Mice deficient for p53 are developmentally normal but susceptible to spontaneous tumors. Nature (Lond.) $356: 215-221$

41. Srivastava, S., Y. A. Tong, K. Devadas, Z.-Q. Zou, V. W. Sykes, Y. Chen W. A. Blattner, K. Pirollo, and E. H. Chang. Detection of both mutant and wild-type p 53 protein in normal skin fibroblasts and demonstration of a shared "second hit" on p53 in tumors from a cancer-prone family with Li-Fraumen syndrome. Oncogene. 7:987-991.

42. Li, F. P., P. Correa, and J. F. Fraumeni, Jr. 1991. Testing for germ line p53 mutations in cancer families. Cancer Epid. Biomarkers \& Prev. 1:91-94. 